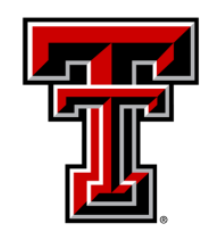

TEXAS TECH UNIVERSITY

Libraries"

\title{
INTERNET RESOURCES FOR TESTS AND MEASUREMENTS
}

\section{The Texas Tech community has made this publication openly available. Please share how this access benefits you. Your story matters to us.}

\begin{tabular}{|l|l|}
\hline Citation & $\begin{array}{l}\text { Quinn, B. A. (1997). Internet Resources for Tests and } \\
\text { Measurements. Internet Reference Services Quarterly, 2(4). } \\
\text { https://doi.org/10.1300/J136v02n04_05 }\end{array}$ \\
\hline Citable Link & $\underline{\text { http://hdl.handle.net/2346/502 }}$ \\
\hline Terms of Use & $\underline{\text { CC-BY }}$ \\
\hline
\end{tabular}


Internet Resources for Tests and Measurements

\author{
Brian Quinn
}

Brian Quinn (libaq@ttacs.ttu.edu) is Social Sciences Librarian at Texas Tech University, Box 40002, Lubbock, Texas 79409. 


\section{KEYWORDS}

internet, resources, tests, measurements, assessment, psychology, education, evaluation 
The reference collections of most research libraries contain a readily identifiable collection of standard paper sources used in locating tests and test-related materials for education and psychology. Yet currently there is no electronic equivalent, no set of internet resources that has been identified as constituting an online literature on tests and measurements. This study attempts to investigate what resources are now available on the internet for tests and measurements, and identifies the most useful ones. In order to keep the study manageable, the emphasis is on resources for psychological testing, with some educational psychology materials included as well. Whenever possible, evaluative summaries of these resources have been included. 
There is a remarkable amount of information about tests and measurements to be found on the internet, if one is willing to spend long hours online tracking it down. Hopefully, this study should eliminate the need for extended searches, as I have tried to include as many worthwhile resources as I have been able to find. Admittedly, it is difficult to offer a comprehensive collection of anything on the Internet, given the rapidity with which it is growing and changing.1 Because of the large volume of resources available, it has been necessary to limit this study primarily to psychological tests and measurements. There are undoubtedly many valuable test resources available on the internet that are specific to education that could not be included in this study.

For easier reference, the resources have been organized into broad categories that give one a clue to their purpose. This study begins with a list of Comprehensive Web Sites that could logically serve as a starting point for any basic search for test information. In order to be considered comprehensive, a resource had to contain many links to other sites specific to tests and measurements. It is the richness and variety of resources that these sites have to offer that make them such a good place to start. Indeed, one site, the ERIC Clearinghouse on Assessment and Evaluation, has so much to offer that it even comes with its own site-specific search engine.

The next category of internet resources, Research and Reference, features factual information about particular tests, test terms, and the science of testing as well. There is also information in this section regarding research strategies for finding test information. Many of the standard reference works used in finding test information are complex and difficult to use, 2 and this section includes pointers on how to use these works and how they are organized. There is also considerable information in this section about the 
effectiveness of particular tests, and sources of funding. Both the librarian needing information about a test or testing, and the student needing help in locating test information will find this section of value.

The following section covers journals and newsletters related to tests and measurements. Currently, only a few journals cover this area, and some like Rasch Measurement Transactions, are quite specialized. Several of these publications are available online, so that the searcher can access the actual full text of the article. Scanning these publications is a good way to obtain an overview of some of the current issues involved in the field of testing. Since many of the articles include bibliographies, monitoring these publications can be a way of finding related sources.

The next group of resources that will prove useful to researchers in the field is that of electronic discussion lists, or "listservs." There are several that particularly emphasize tests and measurements, and most seem to be for specialists with considerable background in assessment. They can be a valuable resource for the researcher who is searching for esoteric or technical information regarding tests and needs the advice of a forum of experts who might be willing to share their expertise in response to a particular query from a searcher.3 However, they will also prove to be of interest to the person seeking more background regarding a particular aspect or technique of testing, as much can be learned from reading the electronic dialogue of experts conversing about topics of importance to them. One unfortunate disadvantage of listservs is that a few are relatively inactive, making them less fruitful sources of information.

The field of testing is rather poorly represented in the category of usenets. The one usenet that does have bearing on the subject is mentioned in this next category, and 
the searcher will find much here of interest related to personality testing. Of course, other usenets in the field of psychology make occasional mention of testing topics, but none with enough frequency to merit mention here as a bona fide test resource.

In the category that follows, the reader will find internet resources devoted to specific organizations that are prominent in the field of tests and measurements. Organizations such as the APA and the Buros Institute are very influential and active in the field,4 and the searcher who needs to find test-related information will find much here of interest. The material to be found at these sites ranges widely in its sophistication, and one can find everything from very basic test information, to cutting-edge research. Presumably, these organizations might also serve as reference points for inquiries about a particular topic related to their interests.

The final category, Test-Specific Resources, contains more in-depth material about particular tests. Included here are a wide range of personality tests, many of which are offshoots of the well-known Myers Briggs Type Indicator,5 which attempts to determine the personality type of the test subject. Other tests try to measure the intelligence quotient, or "IQ" of the subject. There are even tests that are available to measure a person's style of learning or spending personality. Many of these tests are available in online interactive format, allowing the subject to actually take the test online, usually by clicking on one of several possible responses to a multiple choice question. Several of the tests also feature online scoring, which allows the subject to click on a submit button after completing all the questions. The questionnaire is then scored on a computer and returned electronically to the subject. These tests should prove valuable not only to those seeking to learn more about their personality or IQ, but also those 
seeking to learn more about test design and construction. Given the ease of administration and scoring that these online tests offer, it is likely that many more will appear in the near future, and perhaps someday even established tests like the SAT and the GRE will be routinely administered online.

\section{COMPREHENSIVE WEB SITES}

Assessment and Evaluation on the Internet

http://www.cua.edu/www/eric_ae/intass.html

This Web site may have the best collection of resources for tests and measurements currently available on the World Wide Web. It was created to help 
professionals quickly identify internet resources of special interest to researchers in the assessment field. AEI has divided these resources into two categories: gopher sites and listservs. Each category is prefaced by a helpful definition and description of the type of resource and how to use it. Resources are arranged alphabetically by title within each category. Many of the resources are accompanied by a paragraph-length abstract describing the resource. These abstracts are primarily of a descriptive nature and do not attempt to evaluate a given resource to any significant degree. 6

The first category of resources covers gopher sites, and features links to dozens of useful sites, including professional associations like the American Educational Research Association, and the American Evaluation Association. Oddly, some of the most valuable resources, like the Clearinghouse for Subject-Oriented Internet Resource Guides, do not have abstracts. A few of the links, such as the MMPI link, appear to be inactive. There is nonetheless much valuable information, including links to online journals and newsletters, research centers, and statistics software. The second category is devoted to listserv discussion groups. Most of the listservs are accompanied by a brief description of the list. There are many education and social sciences research listservs in this category, and some of the listservs appear to be relevant to psychology.

Assessment and Evaluation on the Internet should be one of the first stops on the Web for anyone interested in getting an overview of the wide variety of resources available to anyone interested in tests and measurements. Few other sites on the internet offer as many resources for tests and measurements in a single location as this one. 


\section{Eric Clearinghouse on Assessment and Evaluation}

http://www.cua.edu/www/eric_ae/

This Web site offers a huge amount of information related to tests and measurements. The site opens with a series of links to ERIC (Educational Resources Information Center). There is a list of known web, gopher, and telnet sites that are valuable for searching ERIC, RIE, and CIJE.

Even more useful for research on tests and measurements is the ERIC/AE Test Locator. It is jointly sponsored by ERIC, the Educational Testing Service, the Buros Institute of Mental Measurements, the University of Nebraska, and Pro-Ed Test Publishers. The ERIC/AE Test Locator provides links for searching the ETS Test Collection database, 7 which now contains over 10,000 records on tests and research instruments. The records describe the tests and provide information about their availability. There is also a link to the Buros Test Review Locator, which tells you which publications of the Buros Institute contains reviews and descriptions of the test you are searching for. A similar test review locator for Pro-Ed publications is also available, as well as a test publisher locator.

Other useful links that are available at this site include a searchable database of over 1,700 full-text articles posted at the ERIC/AE gopher site. Another helpful link provides access to a searchable database of the 1996 annual meeting of the American Educational Research Association. There is also a link to the Language Tester's Guide to Cyberspace, which itself provides numerous links to resources related to applied linguistics and language testing sites. 
The ERIC Clearinghouse on Assessment and Evaluation has a separate gopher for news about testing, and one that features essays, bibliographies, and resources about testing. It has a collection of online guides and FAQ's on assessment, evaluation and learning theory. There is information about testing projects, a directory of educational researchers, and links to assessment resources for K-12 students. All of these resources make The ERIC Clearinghouse on Assessment and Evaluation one of the most useful sites for tests and measurements available on the World Wide Web.

\section{$\underline{\text { Mental Health Net-Assessment Resources }}$}

http://www.cmhc.com/guide/pro01.htm\#other

This is a Web site that offers numerous links to assessment information. The emphasis is primarily on psychological tests, particularly personality assessment instruments. Tests are arranged alphabetically by title, and several tests are accompanied by brief descriptions of what the test is about. Sixteen links to tests resources are featured at this site.

Among the test resources to be found here is a link to the Child Behavior Checklist gopher site. The Child Behavior Checklist is a questionnaire used by psychologists to help assess children's problems.8 The site describes the test, offers bibliographic information about studies performed on the test, and describes information manuals that provide instructions about how to use the test.

Also featured at this site is an online version of The Ennegram Test, which is a test designed to categorize personality into one of nine types. There is a link to the 
Kiersey Temperament Sorter, which is a test that measures personality types in the same vein as Meyers-Briggs, and a link to a series of neurological rating scales. A link has also been provided to a downloadable version of the Personality Diagnostic Questionnaire for DSM-IV, which is useful for detecting the presence of personality disorders using the framework of DSM-IV, Axis II.

One can find here reviews and excerpts of tests such as the White Sands Personality Test 1.4 and the Meyers-Briggs personality test. There are also links to Wada testing, a neurological test used to assess cerebral functioning in the postoperative phase of epilepsy surgery, and the Zang Personality Test, which uses shapes to measure personality types. With such a wide variety of links to tests and test information, Mental Health Net-Assessment Resources is an excellent source for someone searching for a particular scale, as well as for someone who just wants to get an overview of what is available in this area.

\section{$\underline{\text { Neuropsychology Central-Neuropsychological Assessment }}$}

http://www.premier.net/ cogito/neurocen/neuroass/neuroass.html

Neuropsychological Assessment is a comprehensive Web site offering numerous links to sources of information related to the measurement of the neurologically impaired. The site begins with links to behavior analysis and geriatric assessment resources at New York University. It was created to provide psychiatrists with a site to test their 
understanding by offering a series of board-style questions, and annotated answers online. Access to the material is limited to NYU students, however.

For those interested in the measurement of children, there is a link that provides information about a test used in the neurological assessment of pediatric patients. The test is used for conditions like coma and acute neurological deterioration. There is another link that treats the whole subject of neurological assessment and treatment in more general terms and gives useful definitions of such key concepts as diagnostics, assessment of treatment efficacy, delineation of functional capabilities, and cognitive remediation.

Also featured at this site is a course description for Patient Oriented Neuropsychiatric Assessment, and a link to the APA journal Psychological Assessment. There is a study of the relationship between two well-known severity scoring systems for brain-injured patients, and a set of links to the web sites of some leading neuropsychological tests. These include the Ackerman-Banks Neuropsychological Rehabilitation Battery and the MBTI Identification Checklist. There is also a link to a site that features a list of important neurological rating scales, complete with descriptions and actual scale samples.

\section{Yahoo-Education:Educational Standards and Testing}

http://www.yahoo.com/Education/Educational_Standards_and_Testing/

Yahoo offers a very useful and well-chosen set of links related to Educational Standards and Testing. It begins with a list of companies that offer test preparation 
services to candidates in a variety of fields, including law, medicine, business, liberal arts, and English as a foreign language. This is followed by a dozen links to established sites such as the Buros Institute, the ETS Gopher and the ERIC/AE Test Locator.

A number of interesting sites that are less well known can be found here as well. There is a link to CRESST, the National Center for Research on Evaluation, Standards, and Student Testing at UCLA, which provides information about assessment alternatives in American schools. Information about ICAP, the Inventory for Client and Agency Planning, is listed here too. This measure assesses adaptive and maladaptive behavior in children and adults with developmental disabilities.9

Along with these links, one can also find a connection to Immex, the Interactive Multi-Media Exercises project at the UCLA School. This project involves using a software program that analyzes student performance in problem solving activities as an alternative to traditional multiple-choice questionnaires. There is a link to the National Association of Test Directors, an organization that shares information about testing in education, particularly at the elementary and secondary levels. This site offers a particularly good array of links to other ed psych resources on the Web.

Other interesting links that can be explored at Yahoo are Question Mark, a company that provides software that enables the user to create, administer, and analyze tests using a computer, and Roc Research. The latter is a company that writes test questions for teachers and textbooks. Overall, Yahoo may not be as large as some of the mega-sites mentioned previously, but it offers a useful and substantial collection of links that are not easily found elsewhere. Anyone interested in educational testing should find this a valuable site. 


\section{RESEARCH AND REFERENCE}

\section{A Glossary of Measurement Terms}

gopher://vmsgopher.cua.edu/00GOPHER_ROOT_ERIC_AE\%3A\%5B_EDIR.GUIDE\%5 D1AAJGUIDE.txt

This is an excellent site for anyone seeking definitions of technical terms used in testing research. Approximately 30 terms are featured at this site. Terms are arranged alphabetically in a dictionary-style format. Each definition is brief and averages two to four lines. The definitions are clear and succinct.

There is a wide range of material represented, ranging from basic test terms to more technical ones. Basic terms include items like "achievement test," "age norms," "average," and "battery." Among the more technical terms that can be found here are "criterion-referenced test," "normal curve equivalent," and "stanine." This site should prove to be particularly valuable to those who are new to the field of testing and are not very familiar with the specialized terminology. One wishes that more terms could be included, so that this resource could be more comprehensive.

\section{$\underline{\text { Assessment Digests Table of Contents }}$}

http://www.uncg.edu/ ericcas2/assessment/toc_assessment.html

This site, which is co-sponsored by the ERIC Counseling and Student Services Clearinghouse and the University of North Carolina, Greensboro, features over 30 
scholarly articles or digests on a wide variety of topics on assessment. Each article

averages 10-12 pages in length, and most of the authors have academic affiliations. Some of the topics covered include understanding client concerns in mental health counseling, assessment of abilities, interests, self-concept, and temperament, gender and multicultural differences in testing, ethics in assessment, computer-assisted testing, and evaluating career assessment instruments. This site is an excellent resource for the researcher who wants to get a brief overview of a particular aspect of testing by a specialist in that area.

\section{Cresst/UCLA Research on Evaluation and Testing}

gopher://gopher.cse.ucla.edu/1

This gopher server is sponsored by the National Center for Research on Evaluation Standards, and Student Testing (CRESST) at UCLA. It provides information about K-12 assessment research conducted by the Center . Researchers will find an extensive collection of technical reports on test effectiveness, assessment procedures, test construction, and related topics. CRESST also provides access to articles from its newsletter on performance assessment and a huge database on alternative assessment research.10 There is information about upcoming CRESST conferences and proceedings of recent conferences. Information about various CRESST products such as videotapes and books related to assessment is provided. A list of research and funding sources in the field of education is another valuable feature of this site. The server also includes a link to the ERIC database. There is an enormous amount of research available at this server, 
which will be of particular interest to those working in the field of educational psychology and related areas.

\section{Frequently Asked Questions (FAQ) on Psychological Tests}

http://www.apa.org/science/test.html

The American Psychological Association receives many queries about psychological tests and measurements each year. This site contains answers to the most frequently asked questions posed by those trying to locate a certain test or find more information about psychological tests. It is divided into two sections, one answering questions about published tests and another for questions about unpublished instruments. The section on published tests offers suggestions for locating tests on a given subject, where to locate test publishers, and how to obtain computerized testing material. The second section on unpublished tests gives information on locating unpublished tests and discusses some of the responsibilities of users of unpublished tests in relation to copyright issues. Taken as a whole, the many questions answered at this site give the reader an excellent general strategy for locating both published and unpublished tests. It reviews basic test directories and review sources and discusses how to use them, and how to obtain copies from the publisher or author. Of particular value is the section on computerized testing materials used in administering, scoring and interpreting test results. Librarians who want a detailed strategy for locating test information will find this site invaluable. 
$\underline{\text { Job Analysis/Classification and Personality Research }}$

http://harvey.psyc.vt.edu/

A wide variety of information regarding various aspects of testing in the fields of industrial and organizational psychology can be found here. Considerable data is also

provided on the subject of personality testing and research. Some of the material focuses on task-inventory methods 11 and the Common-Metric Questionnaire, a standardized scale for job analysis. Other topics covered include testing and the Americans with Disabilities Act, and software programs used in job analysis and classification. In the area of personality assessment, some of the information focuses on personality tests used in employment-related settings, especially the Myers-Briggs Type Indicator. There are lengthy files on topics such as using item response theory to score the Myers-Briggs, improving the measurement precision of the MBTI, and a discussion of its dimensionality. Those working in the area of industrial/organizational psychology will find this a useful site, as will human resource professionals and students of business and commerce.

The Mental Measurements Yearbook

http://library.uwaterloo.ca/howto/howto22.html

The Mental MeasurementsYearbooks are such an important and complex set of tools for finding information about tests and measurements that the University of Waterloo library has set aside a special section of its Web page to explain them. This site 
begins with a basic description of the Yearbook. It describes the rather complicated cumulative structure of this series of volumes, and then goes on to describe exactly what

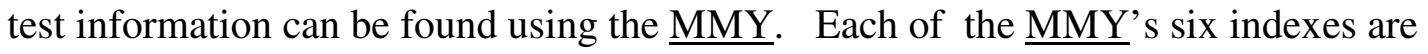
explained briefly. There is a particularly lucid explanation of the potentially confusing score index, which if understood correctly, can prove more useful than searching the title index. The explanation of the name index is equally clear, and is careful to distinguish between persons designated as authors or as reviewers. Overall, this resource gives a valuable summary of how to get the most out of one of the most important sources in testing literature.

\section{$\underline{\text { Social Sciences Review Sources for Tests in Psychology }}$} http://www.colostate.edu/Depts/LTS/research/socsci/ps.html

This resource offers a brief overview of some of the key reference sources used in locating tests and measurements. Eight titles are listed, including standard sources like The Mental Measurements Yearbook, Tests in Print, and The ETS Test Collection Catalog. Each citation is accompanied by a brief abstract describing the contents of the work and how it is arranged. The site includes works covering both published and unpublished tests. This can be useful for researchers desiring a quick snapshot of some of the key sources available. The list is not comprehensive, however, and some of the entries need to be updated with the latest editions. 
Tests and Measurements: A Guide to Resources and Their Use http:// luna.cc.lehigh.edu/BIBLIO:/home/inref/tests.txt

Anyone seeking a detailed online guide to a variety of reference sources used in searching for tests and measurements will find this a worthwhile site to visit. It was created by librarians at Lehigh University, and it provides the user with a fairly complete search strategy for locating test materials. Not only does it provide citations and abstracts describing seminal reference works like Tests in Print, $\underline{\text { Test Critiques, and The Mental }}$

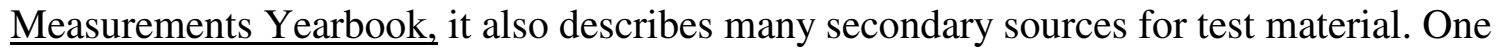
particularly valuable feature of this site is that the descriptions of reference works on tests include sample entries which helps make these works easier to use. This site also gives suggestions about which subject headings to use in searching, describes how to use social sciences indexes for finding test information, and tells how to use the ERIC gopher site on tests and measurements. It also shows how to search for a test when one has only partial information. This resource guide should prove useful to the librarian who is not familiar with how to search for test information, and it might also serve as an excellent online tutorial for students in psychology or education.12 A bit more material on unpublished tests and a listing of sources containing actual test samples would make this site even stronger.

\section{JOURNALS AND NEWLETTERS}




\section{$\underline{\text { About Psychological Assessment }}$}

http://www.apa.org/journals/ass.html

Psychological Assessment is a relatively new journal sponsored by the American Psychological Association. It contains articles, case studies and reviews on the construction, validation and evaluation of tests, with particular attention paid to issues of testing in cross-cultural and gender-related contexts. This site contains detailed information about the journal, which is currently issued in paper format. In addition to describing Psychological Assessment, it contains the table of contents of current and past issues, information about how to submit manuscripts for review, and particulars about prices and subscriptions. The site even features an order form that can be printed and mailed by someone wishing to subscribe. Anyone interested in tests and measurements will want to know more about this promising new journal, and this site is an excellent starting point.

\section{$\underline{\text { Rasch Measurement Transactions }}$}

gopher://vmsgopher.cua.edu/11gopher_root_eric_ae\%3a\%5b_rasch\%5d

$\underline{\text { Rasch Measurement Transactions }}$ is an online journal of current information about Rasch measurement, which utilizes quantitative techniques to analyze qualitative data.14 It is published quarterly by the American Educational Research Association. The content consists of abstracts, reviews and brief articles on both the theoretical and applied aspects of Rasch measurement, especially in relation to multiple choice testing, questionnaire analysis, computer adaptive testing and performance assessment. This site features an 
introduction to Rasch modeling, a membership form for the Rasch SIG of the AERA, and the tables of contents and actual full text of articles appearing in the last ten issues. Most of these articles are highly technical in nature, and will be of interest primarily to educational psychologists and psychometricians. Many of the articles are accompanied by a bibliography and the database is searchable by keyword.

\section{TIP:The Industrial-Organizational Psychologist}

http://cmit.unomaha.edu/TIP/TIPOct95/schneide.html

An important part of industrial/organizational psychology is testing, 13 and TIP is an electronic newsletter that includes full-text articles about tests and measurements in many of its issues. TIP is the official quarterly of the Society for IndustrialOrganizational Psychology. It was created to provide subscribers with the latest research findings in industrial and organizational psychology. The latest issue features an article on testing for integrity, and back issues are also available at this site. Previous issues include articles about the Office of Personnel Management updating its guide for testing persons with disabilities, and about the changes in educational and psychological testing being proposed by the AERA, APA, NCME Joint Committee on the Standards for Educational and Psychological Testing. TIP is a very valuable site for those doing research in I/O psychology, at both the undergraduate and graduate levels. 


\section{$\underline{\text { LISTSERVS }}$}

$\underline{\text { Idanet }}$

mailbase@mailbase.ac.uk

Idanet (Individual Differences and Assessment Net) is a moderately active discussion group whose members are interested in the testing of individual differences. Specifically, the focus is on using multivariate analysis to measure intrapsychic variables such as personality and cognitive ability and attempting to explain the variance among different individuals. The broad theme of the discussion makes it appealing to a wide variety of researchers from different specialties in the social sciences, including both clinical, experimental, industrial, and educational psychology. The discussion is therefore wide ranging and can include anything that falls within the realm of individual differences. Some recent topics of discussion among this group include the use of Rasch models in ability testing, whether intelligence is different from personality, the posting of a Web page by the Personnel Testing Council of Metropolitan Washington, D.C. and news about an upcoming conference on the rights and responsibilities of test takers. Much of the list discussion can be fairly technical, so it appears more appropriate for graduate students and professionals.

\section{Personality Type Mailing Lists}

http://www.brad.ac.uk/ mdavarle/e-lists.html 
This site provides a listing of listservs, each of which is dedicated to the discussion of a different personality type. All of these lists stem from sixteen possible personality types measured by the Myers-Briggs Type Indicator, a test which measures personality along four basic dimensions: extroversion, introversion, sensing, and intuition.15 This theory of personality assumes that one function is always dominant, and the result is 16 possible personality combinations. There are nine listservs to be found at this site, each of which focuses on a dominant personality type. The list is annotated, and includes a brief description of the list, the name of the list administrator, the number of subscribers, and information about how to subscribe. Subscription to some of the lists is limited to members who have that particular personality type.

\section{$\underline{\text { Rorschach }}$}

\section{LISTSERV@sjuvm.stjohns.edu}

Rorschach is a highly active discussion list that covers a variety of topics related the technique of Rorschach testing, which is used to test personality. The technique consists of ten cards containing ink blots, which the subject is asked to interpret freely.16 The interpretations are than encoded with the aid of a system of interpretation, which allows one to arrive at an assessment. Subscribers to this list include practicing psychologists as well as many graduate students in the area of clinical psychology. Because the language used is often technical, this is not an appropriate list for laypersons. In addition to discussion of Rorschach testing, other projective tests are occasionally mentioned on the list. Some of the postings to the list that have appeared recently include a discussion of inter-rater reliability, a new book recommendation, using the Rorschach 
with children, Rorschach training workshops, determining the amount of time necessary to administer, score, and interpret the test, and the overinterpretation of color shading blends in certain cards. This list should be of interest of anyone interested in projective tests and how to use them effectively.

$\underline{\text { Validata }}$

\section{LISTSERV@UA1VM.UA.EDU}

The subject of this discussion list is the development, testing, and validation of psychological measures. It was established to serve as a forum for discussion of topics related to tests of personality, particularly multiple choice tests. Topics of particular interest to the list include methods of improving tests, psychometric flaws in existing instruments, face validity issues, the use of confirmatory factor analysis techniques to purify measures, and constructs that require measurement improvement. The list should prove to be of interest to researchers interested in improving test measurement and developing new scales. The list is unmoderated, and at the time the author subscribed to it, largely inactive.

\section{USENET NEWSGROUPS}

alt.psychology.personality

news:alt.psychology.personality 
The alt.psychology.personality newsgroup is based on the same personality typology that is used in the Myers-Briggs Type Inventory. Indeed, many of the postings are from people who have taken the MBTI and whose test results have indicated they are one of the 16 personality types measured. So one will find postings speculating about what Hitler's personality type might have been, whether introverted personality types need to be around others, whether gifted introvert-type children are more likely to pursue scholarly occupations, etc. There are also postings about people seeking more information about a particular personality type (usually their own) or about the test itself. Despite the heavy emphasis on Myers-Briggs, it appears that the group is unmoderated, and there are many messages about topics unrelated to testing that span a wide range of psychology topics. This newsgroup is nonetheless valuable for those interested in Myers-Briggs testing and the concept of personality typing.

\section{ORGANIZATIONS/INSTITUTIONS}

\section{American Psychological Association}

http://www.apa.org/

The web site of the American Psychological Association is a good source of information about recent research and trends in testing. There is a link here that allows 
the viewer to search the PsycINFO database, which is an excellent source of data about tests and measurements. Reviews, both pro and con, can be found here about the most controversial book recently published on the subject of testing, The Bell Curve.18 A copy of the Code of Fair Testing Practices is also available. The best way to locate test information is to use the search link located at the end of the site. Typing in a simple search term like "tests," will bring up instructions for how to find test information in libraries, information about graduate study in educational and psychological measurement, an abstract describing the APA publication Psychological Testing of Hispanics, and other resources related to testing. The APA site is thus a valuable resource for anyone seeking general information about testing.

\section{Association for Psychological Type}

http://www.aptcentral.org/

The APT is an association of persons interested in the study of psychological types. It attempts to promote the theory and application of psychological typing through education and research, and also advocates the ethical use of test instruments based on psychological typing. This site gives information about the benefits of membership, such as staying current with the latest developments in the Meyers-Briggs Type Indicator. The APT also offers continuing education for psychologists in administering and interpreting the MBTI. The association holds meetings and conferences and publishes the Bulletin of $\underline{\text { Psychological Type and the Journal of Psychological Type, as well as biennial conference }}$ 
proceedings. The site includes an online membership application that can be printed out and mailed.

\section{The Buros Institute}

http://www.unl.edu/buros/home.html

This is very useful site that is sponsored by The Buros Institute of Mental Measurements at the University of Nebraska. It opens with a description of the Institute and an explanation of its goals and purposes, and how it goes about accomplishing them.17 This introduction is followed by a series of links to other test resources. There is a link to the Buros Test Review Locator, which indexes Buros publications like the Mental Measurements Yearbook and Tests in Print. The Locator enables a searcher to quickly identify which Buros publication a review of the test can be found in, by typing in key words and clicking on the "Submit Query" option. This site also includes detailed online guides to using the Mental Measurements Yearbook and Tests in Print. Another link features a list of Buros publications complete with ordering information. Other information available includes details about $\underline{\mathrm{MMY}}$ on Silverplatter, free user's guides, a schedule of forthcoming publications, articles and reviews about Buros publications, and more. This is the best site for information about Buros publications and the Buros Institute. It will appeal to anyone who uses tests and measurements, from undergraduates to post-doctoral researchers. 


\section{Jefferson Psychometric Lab}

http://kiptron.psyc.virginia.edu/

This resource not only includes information about tests and measurements, it also includes data regarding the use of quantitative methods in psychological research. The lab, which is affiliated with the Psychology Department at the University of Virginia, specializes in researching new methods for experimental design and the computerized analysis of data. This site features summaries of recent research that the lab's researchers have been involved in. Some of the lab's current research topics include decision validity methods applied to the assessment of brain disorders with the WAIS, and an investigation of the measurement properties of the WAIS using novel structural equation modeling techniques. The research available at this site is highly technical in nature, making this site more appropriate for graduate students and professionals working in the area of quantitative research methods and psychometrics.

\section{Belbin Self-Perception Inventory}

http://www.brad.ac.uk/ mdavarle/other.html 
Technically this site is called "Other Personality Tests," but since it only features one test, the Belbin Team-Role Self-Perception Inventory, it might be more accurate to refer to it by that name. The Belbin Self-Perception Inventory was created to measure a subject's strongest and weakest team roles.19 This site does not feature the actual test, but it does include a form that can be automatically e-mailed for a copy of the test. An online version of the test will then be e-mailed back to the requester, who can then complete it and return it online. This test should be especially valuable to researchers working in the area of industrial and organizational psychology.

\section{$\underline{\text { The Comar IQ Tests }}$}

http://www.euronet.nl/users/cor/iq.html

The Comar IQ tests consists of four separate tests representing four levels of increasing difficulty. Each test features 10 questions designed to measure a subject's level of intelligence. The nature of the questions precludes the use of reference works such as dictionaries or encyclopedias, since most of the questions cannot be answered by consulting them. The test can be completed online, and submitted electronically for scoring. Tests are scored and a person's ranking is posted electronically to a list at the site. Subjects have the option of remaining anonymous if they do not wish to have their e-mail address published. This site should prove useful for anyone interested in measuring their IQ, as well as those interested in studying how an IQ test is constructed. The site could use more introductory background material about how the test was developed. 


\section{The DDLI Page}

http://sunsite.unc.edu/pub/academic/psychology/alt.psychology.personality/html/ddli.html

The DDLI Page is home to the Duniho and Duniho Life Pattern Indicator, an extension of the well-known Myers-Briggs personality test. It measures the same 16 personality types, by posing a series of questions in order to determine the subject's life pattern. The DDLI is still an experimental measure, so there is no published paper version, only a digital one. This web site offers links to Amiga, PC, Unix, Macintosh, and Acorn versions of the test. There is a lengthy introduction of life patterns theory, which is based on Carl Jung's concept of psychological types. This site also includes an extensive series of FAQ's that go into much detail regarding the finer points of the test and what it is supposed to measure.

\section{Emotional Intelligence Quotient}

http://www.utne.com/cgi-bin/eq

Those familiar with the best selling book Emotional Intelligence 20 by Daniel Goleman, will find this site of interest. It begins with Goleman explaining the concept of emotional intelligence, and his belief that it can be measured. This is followed by ten multiple-choice questions that ask a subject how s/he would respond emotionally in a particular hypothetical situation. The questions are followed by a chart for interpreting one's score on the test. An outline of the basics of emotional intelligence is also 
included, along with an answer key with detailed explanations of why a given response is considered appropriate. This is a fascinating site, but it could be better organized (e.g. the answer key should immediately follow the questions rather than be separated by other material).

\section{European IQ Test}

http://oscar.teclink.net/ tektite/iq/html

This is a intelligence test designed to measure IQ scores up to 174 . The test consists of 25 questions, which are of the sequence-completion type. For example, many of the test questions ask the subject to complete sequences of numbers or letters or pictures (Netscape or Mosaic are necessary to complete the test). The test is designed to be completed in twenty minutes, but because the questions are all of a similar format, it might be completed in less time. Once the test is completed online, it can be submitted electronically and is then scored automatically. The test seems poorly designed given the monotony of the question format and the fact that most of the questions seem designed to measure logical reasoning, which is only one measure of intelligence.21 Nonetheless, those curious about the subject of IQ will find this site worth investigating.

\section{The Keirsey Temperament Sorter}

http://sunsite.unc.edu/personality/keirsey.html

This site is concerned with a personality test developed by Daniel Keirsey, who has adopted elements of Jung's and Myers' approaches to measuring personality types. Keirsey differs from his predecessors in proposing that four temperaments are more basic 
and deserve greater emphasis than the eight types posited by Jung or the 16 types utilized by Myers. Another difference is that the Meyers-Briggs test is a professional instrument and may only be administered by a trained practitioner, while the Keirsey test is available at this site. A viewer can take the test online, and it will be scored automatically. The test itself is a lengthy questionnaire taken from Keirsey's book Please Understand Me: Character and Temperament Types, 22 and consists of 70 randomized multiple choice questions. This site also includes a solid introduction to the theory underlying the test, as well as a helpful bibliography of reference materials on personality typing.

\section{Learning Style}

http://www.gse.rmit.edu.au/ rsedc/learn.html

Learning Style is a somewhat cryptic site because it contains a complete psychological test whose author and source are unknown. The only information provided is that the questionnaire has been converted to digital form by David Chia, who is affiliated with the Graduate School of Engineering at RMIT University in Australia. The test itself is a brief nine-question instrument requiring multiple choice responses. The questionnaire can be completed online, and is automatically scored by computer once it has been completed and the viewer has clicked on the submit button. The questions probe the subjects preferred learning style in a number of different situations, such as decision making, learning a foreign language, and making major purchases. Despite the lack of introductory background material, the test itself is thought-provoking and can be 
instructive. This test will be particularly interesting to those working in the area of educational psychology.

\section{Meyers-Briggs FAQ-A Summary of Personality Typing}

http://sunsite.unc.edu/personality/faq-mbti.html

Anyone wishing to get a quick grasp of the Myers-Briggs test and the psychological theories upon which it is based 23 will find this site quite useful. It is also helpful for understanding other tests that are based on Myers-Briggs and the concept of personality typing, such as the the DDLI and the Keirsey Temperament Sorter. This site is actually mistitled in the sense that the information does not appear in standard FAQ question and answer format. It begins with a detailed summary of personality typing from a broad historical and theoretical perspective. This is followed by detailed descriptions of the four scales used and the 16 personality types measured, preferred vocabulary for the scales, and a bibliography of books, periodicals, and other resources on personality typing. This is likely the best general source of information on personality typing currently on the Web.

\section{Personality Diagnostic Questionnaire-4}

http://www.travel-net.com/ alphalog/

The PDQ-4 is a test used for detecting the presence of personality disorders, based on Axis II of the DSM-IV. It is intended for use by practicing professionals in the mental health field. The predecessor of the PDQ-4, the PDQ-R, has been widely used and 
extensively researched.24 This version, the PDQ-4, evaluates several different types of personality disorders-the schizoid, depressive, and histrionic-narcissistic, as well as the avoidant-dependent, obsessive-compulsive, and negativistic-depressive disorders. By clicking on a link at the site, one is able to download a copy of the paper and pencil version of the test, which is free for unlimited use. A hard copy can also be obtained from the publisher, whose e-mail address is included. The test is only sent to addresses that indicate an academic or professional affiliation. This site also contains links to other services that the publisher provides, such as questionnaire design and evaluation. PDQ-4 provides links to several other internet resources for psychology and psychiatry as well.

\section{The Personality Index}

http://www.astro.washington.edu/ingram/mbti/index.html

The Personality Index is another web site based on the Jungian concept of personality types.25 It includes a number of links to personality type resources, which have all been mentioned elsewhere in this study. Its particular contribution is to provide a listing of links to home pages organized by personality type. Doug Ingram, who maintains the site, sees the page as a test of the validity of the concept of personality typing. Specifically, it appears to be an application of the Meyers-Briggs Type Inventory. The typing at this site corresponds to the 16 personality types used in the MBTI. Each type has two links. One link connects to a set of links to home pages of people whose test results suggest that they are that type. The other link provides an explanation of that particular type along with examples of famous people through history who have 
exemplified that type. Those interested in testing based on personality types will find this page interesting, and anyone who is uncertain about what their personality type is can get an idea by trying the Keirsey Temperament Sorter, mentioned earlier in this study.

\section{$\underline{\text { Rorschach Inkblot Test }}$}

http://www-students.biola.edu/ markm.rorsch.html

This site contains several links to Rorschach-related material. It begins with a rather ingenious and entertaining online version of the Rorschach called "cyber-blots." This consists of ten Rorschach-like patterns created by using the symbol keys on the computer keyboard. Another link is titled "The Exner Bible" a reference to John E. Exner, who pioneered one of the most significant advances in the development of the Rorschach by devising a comprehensive system for scoring and interpreting the test in the 1970's.26 There is also a link to a proposed internet relay chat group for Rorschach issues (at the time of this writing the channel had been applied for). Another useful feature of this site is a history of the Rorschach test, and a link to a bibliography of nonExnerian interpretive schemas. This is an important site for anyone interested in projective testing, particularly faculty and students working in the areas of clinical and counseling psychology. 


\section{Spending Personality Assessment}

http://www.ns.net/cash/selftest//selftest.html

This is an online interactive test that is designed to help a subject understand his or her subconscious spending patterns or "spending personality." The author of the test, a certified financial planner, believes that errors in money management stem from seven unconscious patterns, and that most people have a dominant spending personality. The test consists of 26 Likert-scale type questions that are divided into seven categories: fanatical shopping, impulsive buying, passive buying, avoidance shopping, esteem buying, overdone buying, and hot potato buying. Each category of question is followed by a set of links corresponding to one's score range, which connect to explanations of what that score means. This test may prove useful to those in applied areas of psychology, especially counseling psychology.

\section{$\underline{\text { VALS Questionnaire }}$} http://future.sri.com/VALS/survey.html

This is a test created by SRI Consulting, a marketing research firm interested in measuring consumer values and lifestyles (VALS). The test is designed to measure consumer self-orientation, 27 based on the theory that consumers are motivated to purchase products by one of three basic self-orientations: principle, status, or action. Principle-oriented consumers purchase on the basis of ideas, while status-oriented purchasers attempt to demonstrate their success to peers. Action-oriented consumers are motivated to purchase products by a desire for physical or social activity. The VALS 
questionnaire attempts to measure a subject's VALS type based on online responses to 42 multiple-choice questions. Once completed, the questionnaire can be submitted online, and upon receipt is processed in a matter of minutes. This site should prove especially interesting to anyone working in the area of industrial and organizational psychology.

\section{$\underline{\text { Summary }}$}

This study represents one of the first attempts to explore the rapidly growing body of resources that now exist for tests and measurements on the internet. It can be seen that there is a surprisingly large amount of information available having to do with tests and measurements. Much of this material is education-related, but there is a large and growing literature related to psychological tests and measurements. Within the field of psychology, it is personality testing that is most predominant on the internet. Tests measuring personality type are by far the most prevalent, and several of the major test instruments are represented by one and in some cases several sites. 
Many of these internet resources complement or supplement the existing paper resources covering tests and measurements that are typically found in the reference section of most research libraries. These include valuable electronic guides to classic reference works such as Tests in Print and The Mental Measurements Yearbook. Some sites even feature overviews of the reference literature on testing and have been clearly designed as aids to students in search of information about a particular test. But perhaps the most exciting discovery is that there are not just test resources, but the actual tests themselves to be found on the internet. Some of these exist as online interactive versions that can be completed, submitted, and scored electronically, without the need for paper or pencil. This suggests that the internet may now serve as a testing ground for a form of "virtual testing" that may one day become standard practice.28 For now though, it can be safely said that the internet has much to offer anyone searching for information about tests, how to find tests, or even the tests themselves. 


\section{$\underline{\text { NOTES }}$}

1. Richard W. Wiggins, “The Unfolding Net: The Internet's Massive Growth

Continues to Drive Commerce and Innovation," Internet World 6 (November, 1995):42-

45.

2. Robert P. Jordan, "Searching for Information on Tests," The Reference

Librarian 48 (1995): 199-221.

3. Deborah C. Sawyer, “A Matter of Confidence: Asking Reference Questions

Over the Internet," Online 17 (July, 1993):8-9.

4. James V. Mitchell, “A Potent Triumvirate: Librarian, Buros Institute, and Test

User,” RQ 26 (Spring, 1987):338-34.

5. David J. Pittenger, “The Utility of the Myers-Briggs Type Indicator,” Review of Educational Research 63 (Winter, 1993):467-488.

6. Thomas Childers, "Evaluative Research in the Library and Information Field," Library Trends 38 (Fall, 1989):250-67.

7. Susan Klingberg, “Online Access to Tests: the ETSF and MMYD,” Reference Services Review 12 (Winter, 1984):15-19.

8. Gregg M. Macmann, David W. Barnett, Steffani A. Burd, Trina Jones, et al., “Construct Validity of the Child Behavior Checklist: Effects of Item Overlap on SecondOrder Factor Structure,” Psychological Assessment 4 (March, 1992):113-116.

9. Kevin S. McGrew, Robert H. Bruininks, Martha L. Thurlow, "Relationship Between Measures of Adaptive Functioning and Community Adjustment for Adults With Mental Retardation,” Exceptional Children 58 (May, 1992):517-529. 
10. Ana Huerta-Macias, "Alternative Assessment: Responses to Commonly Asked Questions,” TESOL Journal 5 (Autumn, 1995):8-11.

11. Richard D. Arvey, Eduardo Salas, Kathleen A. Gialluca, "Using Task Inventories to Forecast Skills and Abilities," Human Performance 5:3 (1992):171-190.

12. Josey Y.M. Chu, William L. Palya, Donald E. Walter, "Creating a Hypertext Markup Language Document for an Information Server," Behavior Research Methods, Instruments and Computers 27 (May, 1995):200-205.

13. Thomas K. Fagan and Gary R. VandenBos eds., Exploring Applied Psychology: Origins and Critical Analyses (Washington, D.C.: American Psychological Association, 1993):83-118.

14. Scott Snyder and Robert Sheehan, "The Rasch Measurement Model: An Introduction," Journal of Early Intervention 16 (Winter, 1992):87-95.

15. David M. Karesh, Walter A. Pieper, Clarence L. Holland, "Comparing the MBTI, the Jungian Type Survey, and the Singer-Loomis Inventory of Personality," Journal of Psychological Type 30 (1994):30-38.

16. Andrew M. Colman ed., Companion Encyclopedia of Psychology (London: Routledge, 1994):1301.

17. Barbara S. Plake, Jane C. Conoley, Jack J. Kramer, Linda U. Murphy, "The Buros Institute of Mental Measurements: Commitment to the Tradition of Excellence," Journal of Counseling and Development 69 (May/June, 1991):449-455.

18. Richard J. Herrnstein and Charles Murray, The Bell Curve: Intelligence and Class Structure in American Life (New York: Free Press, 1994). 
19. Adrian Furnham, Howard Steele, David Pendleton, “A Psychometric Assessment of the Belbin Team-Role Self-Perception Inventory," Journal of Occupational and Organizational Psychology 66 (September, 1993):245-257.

20. Daniel Goleman, Emotional Intelligence (New York: Bantam Books, 1995).

21. Robert J. Sternberg, Richard K. Wagner, Wendy M. Williams, Joseph A. Horvath, et al., "Testing Common Sense," American Psychologist 50 (November, 1995):912-927.

22. David Keirsey, Please Understand Me: Character and Temperament Types (Del Mar, California: Prometheus Nemesis, 1984).

23. Mary H. McCaulley, "The Myers-Briggs Type Indicator: A Measure for Individuals and Groups," Measurement and Evaluation in Counseling and Development 22 (January, 1990):181-195.

24. Jayne Patrick, Paul Links, Rob Van Reekum, Janice E.M. Mitten, et al. "Using the PDQ-R BPD Scale As a Brief Screening Measure in the Differential Diagnosis of Personality Disorder," Journal of Personality Disorders 9 (Fall, 1995): 266-274.

25. C.G. Jung, Psychological Types (Princeton University Press, 1971).

26. John E. Exner, Leon S. Martin, "The Rorschach: A History and Description of the Comprehensive System," School Psychology Review 12 (Fall, 1983):407-413.

27. Thomas P. Novak, Bruce MacEvoy, “On Comparing Alternative Segmentation Schemes: The List of Values (LOV) and Values and Life Styles (VALS)," Journal of Consumer Research 17 (June, 1990):105-109.

28. Georg Warzecha, "The Challenge to Psychological Assessment from Modern Computer Technology," European Review of Applied Psychology 41:3 (1991):213-220. 
